\title{
Failure Analysis of X80 Line Pipe's Circumferential Weld
}

\author{
LIU Hong Liang ${ }^{1, \text { a }}$, LI Fang Po ${ }^{2, \mathrm{~b}}$ and DANG En ${ }^{1, \mathrm{c}}$ \\ ${ }^{1}$ CNPC Bao Ji Oilfield Machinery Co.,LTD, Bao Ji Shaanxi 710002, China; \\ ${ }^{2}$ CNPC Tubular Goods Research Institute, Xi' an Shaanxi 710077, China.

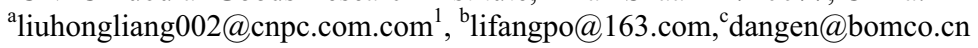

\begin{abstract}
One $530 \mathrm{~mm}$ X80 pipeline weld failed infrequently in service process. This paper gives a systematic analysis in consideration of both material quality and loading condition. Inspection was performed on chemical composition, mechanical performance, metallograghy and micro-morphology. The result shows that weld joint's leakage failure accident is fatigue failure. Under the effect of tensile- tensile stress fatigue stress, fatigue crack originated from weld fusion line near the pipe body and developed along the weld. Porosity defect in the weld reduced its bearing capacity, and promoted the formation and development of the fatigue crack. Fatigue strength and fatigue life of the weld has great relationship with the size and distribution of porosity. The greater the porosity, the more close to surface, the decrease of fatigue life is more obvious.
\end{abstract}

\section{Introduction}

X80 pipeline steel with excellent service performance was widely applied in offshore oil and gas drilling and transportation field in recent years. Weld is the most weak part of pipeline system, and it is also prone to failure. In 2013, one weld leakage failure accident of X80 pipeline occurred in our country infrequentely. In order to analyze failure reason of the weld, we took part of the failed pipeline system and carried out experiment study.

\section{Experiment Methods}

The chemical composition of sample was determined by spectroscopic chemical analysis. The microstructure in various regions was observed by optical metallography. The mechanical properties were conducted according to ASTM standards, and hardness in various regions around fracture was made using a testing system (HV). The crack surface was observed by visual examination and scanning electronic microscopy (SEM).

* Corresponding author: authorliuhongliang002@enpc.com.com 


\section{Results}

Leak failed X80 pipeline weld joints as shown in Fig.1(a). X80 pipeline and the flange joint was welded by the way of TIG welding. The outer side weld residual height was kept intact, while the inner weld surface was machined smoothly. Non destructive testing result show that there was a long crack around the leakage position. Sample for microscope analysis was mechanical treated according to the nondestructive test result. The crack growth surface was observed and analyzed with scanning electron microscope. Larger number of porosity was observed on crack surface, shown in Fig.1(b). Porosity's diameter is about $0.88 \mathrm{~mm}$, and the crack growth surface is characterized by number of fatigue stration, as shown in Fig.2. In the failure position, the wall thickness of both sides of the weld was detected. The thickness of flange was about $14.6 \mathrm{~mm}$, the thickness of pipe was about $14.8 \mathrm{~mm}$, and the inner wrong side of the weld specimen was about $1.1 \mathrm{~mm}$.

Metallographic analysis was carried out on the failed weld joint specimen. The non-metallic inclusions, microstructure and grain size of the specimen material was examined and the examination results was shown in Table 1. The low profile of the weld position is shown in Fig.3. Crack originated from inside weld fusion line of tube body side, and the crack was extended along the weld direct to weld's outside. There was a number of porosity defects in the weld around the crack.
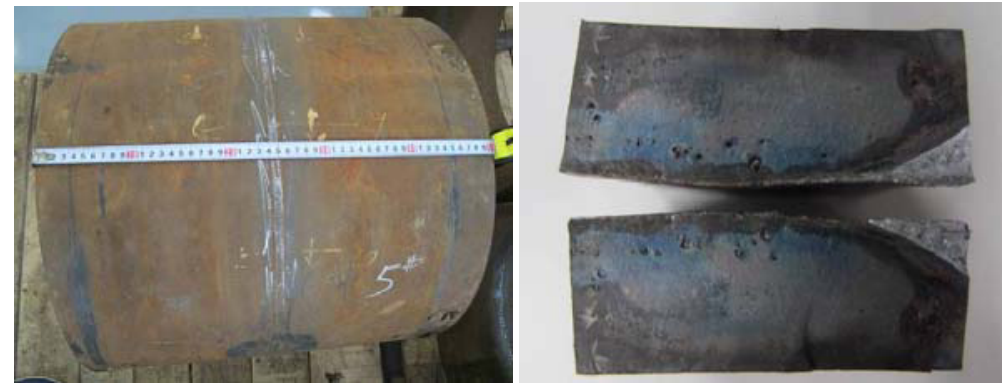

Fig.1 Morphology of failed sample
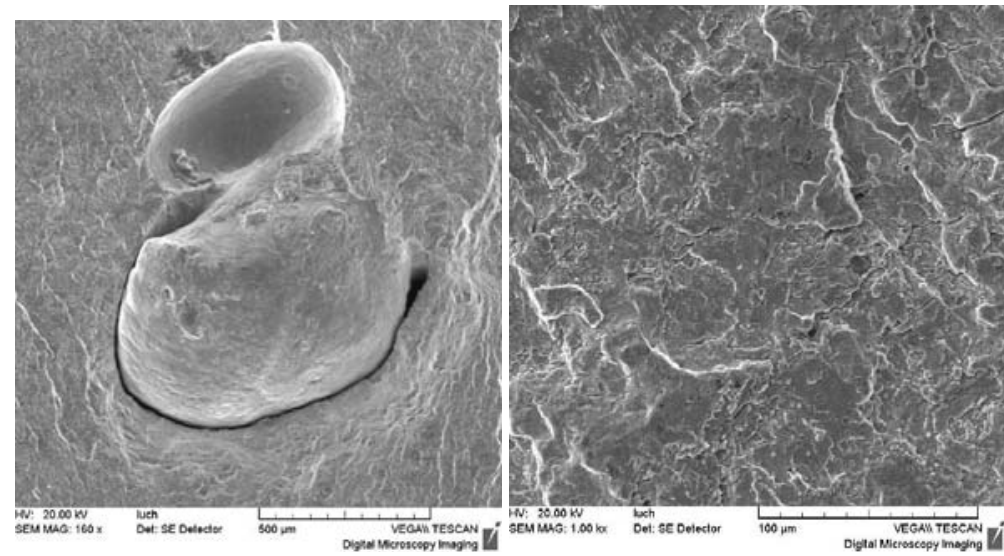

Fig.2 Morphology of crack surface (a)pore (b)fatigue striation 


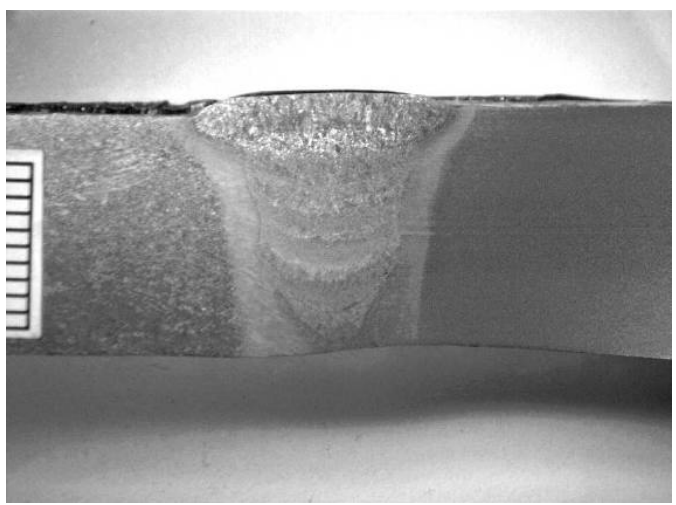

Fig.3 Morphology of failed weld

TABLE 1 MICROSTRUCTURE EXAMINATION OF WELD

\begin{tabular}{cccc}
\hline Position & Weld & Fusion zone & Fine grain zone \\
\hline \multirow{2}{*}{ Result } & Outer weld:B & Pipe side:B & Pipe side: $\mathrm{PF}+\mathrm{P}$ \\
& Internal weld: $\mathrm{B}+\mathrm{F}+\mathrm{P}$ & Joint side: $\mathrm{B}$ & Joint side: $\mathrm{T}+\mathrm{F}+\mathrm{B}$ \\
\hline
\end{tabular}

Chemical composition was detected from both sides of the weld joint. The results showed that the chemical composition of the X80 tube was in accordance with the API Spec 5L:2012 standard[1], and the chemical composition of the flange joint was different greatly.

TABLE 2 CHEMICAL COMPOSITION OF SAMPLE (WT, \%)

\begin{tabular}{ccccccccccccc}
\hline Element & $\mathrm{C}$ & $\mathrm{Si}$ & $\mathrm{P}$ & $\mathrm{S}$ & $\mathrm{Cr}$ & $\mathrm{Mo}$ & $\mathrm{Nb}$ & $\mathrm{V}$ & $\mathrm{Ti}$ & $\mathrm{CE}_{\mathrm{Pcm}}$ & $\mathrm{CE}_{\text {IIW }}$ \\
\hline Pipe body & 0.059 & 0.34 & 0.012 & 0.0010 & 0.02 & 0.16 & 0.045 & 0.0053 & 0.016 & 0.179 & $/$ \\
Flange joint & 0.14 & 0.17 & 0.0092 & 0.0044 & 0.090 & 0.32 & 0.048 & 0.047 & 0.0022 & $/$ & 0.5924 \\
$\begin{array}{c}\text { API Spec } \\
\text { 5L:2012 }\end{array}$ & $\leq 0.12$ & $\leq 0.45$ & $\leq 0.025$ & $\leq 0.015$ & $\leq 0.50$ & $\leq 0.50$ & $\mathrm{Nb}+\mathrm{V}+\mathrm{Ti} \leq 0.15$ & $\leq 0.25$ & $\leq 0.43$ \\
\hline
\end{tabular}

The tensile property, bending property, impact property, nick-break property and hardness of the weld were tested by sampling from the failed weld joint. The impact test was performed at $0^{\circ} \mathrm{C}$, and other experiments were done at room temperature. The test results show that the tensile strength of the weld is about $750 \mathrm{MPa}$, which is more than $625 \mathrm{MPa}$ that the requirement of API Std 1104:2007[2]. Tensile specimen fractured in the position of pipe body and tensile strength of the weld is better than that of pipe. Surface bending 180 degrees, back bending 180 degrees and lateral bending 180 degrees was completed respectively, and no crack or other defect greater than $3 \mathrm{~mm}$ was observed around weld. The nick-break fracture surface of the weld sample is shown in Fig.4. The maximum size of porosity is less than $1.6 \mathrm{~mm}$, and the total area of the porosity is no more than $2 \%$ of total area of fracture. The impact test result of the weld and heat affected zone is shown in table 3 . The impact absorption energy of the weld is and is close to that of the heat affected zone, which is significantly greater than the requirement of related standards[3,4]. The impact fracture surface has a certain brittle fracture character along with many pores. In order to analyze weld's hardness, the hardness of weld's different position is detected according to the Fig.5 and test result is shown in table 4. The hardness of outside weld is higher than that of the inner weld, and the hardness of flange joint heat affected zone is obviously higher than that of the pipe body's heat affected zone. 


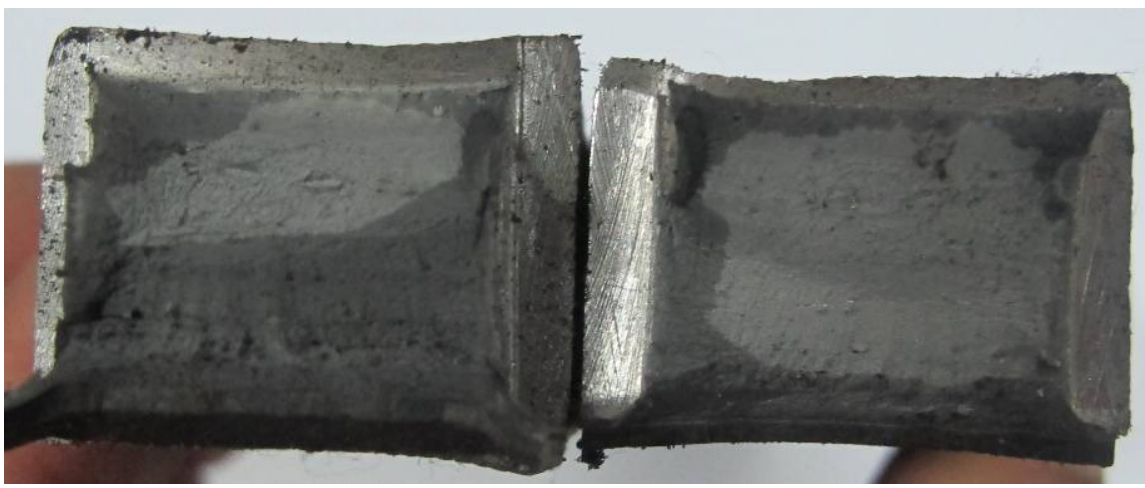

Fig.4 Nick-break fracture surface

TABLE 3 TEST RESULT OF IMPACT ABSORBED ENERGY

\begin{tabular}{cccc} 
& \multicolumn{2}{c}{ Impact absorbed energy $(\mathrm{J})$} & \multirow{2}{c}{$\begin{array}{c}\text { Shear area } \\
(\%)\end{array}$} \\
\cline { 2 - 3 } Item & Single & Average & \\
\hline Weld & $207,185,179$ & 190 & $100 、 85,80$ \\
\hline HAZ of joint & $181,184 、 213$ & 193 & $85 、 95 、 100$ \\
HAZ of pipe & $182 、 223 、 214$ & 206 & $85 、 90 、 95$ \\
\hline
\end{tabular}

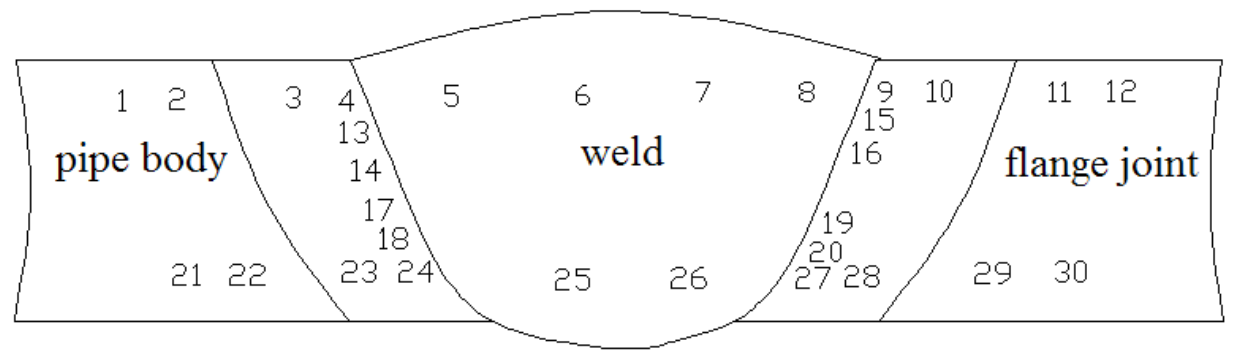

Fig.5 Diagram of hardness test position

TABLE 4 TESTING RESULT OF HARDNESS

\begin{tabular}{cccccccccccccccc} 
Position & 1 & 2 & 3 & 4 & 5 & 6 & 7 & 8 & 9 & 10 & 11 & 12 & 13 & 14 & 15 \\
\hline Hardness & 233 & 229 & 208 & 224 & 278 & 287 & 298 & 284 & 323 & 253 & 258 & 264 & 194 & 204 & 245 \\
Position & 16 & 17 & 18 & 19 & 20 & 21 & 22 & 23 & 24 & 25 & 26 & 27 & 28 & 29 & 30 \\
Hardness & 255 & 191 & 210 & 260 & 253 & 226 & 222 & 206 & 232 & 235 & 236 & 268 & 236 & 243 & 231
\end{tabular}




\section{Analysis of Failure Causes}

From the test results, the chemical composition, tensile properties, impact properties, nick-break property and hardness of the failed X80 pipe weld samples meet the requirement of related standards. From the field data, it is found that the failed weld joint is mainly subjected to cyclic tensile-tensile stress in service process. Circumferential weld's failure is fatigue failure. Fatigue crack originated from the weld fusion zone of pipe body, and extended to the outer weld surface vertically. Large number of pore in the weld promoted the formation and propagation of fatigue crack.

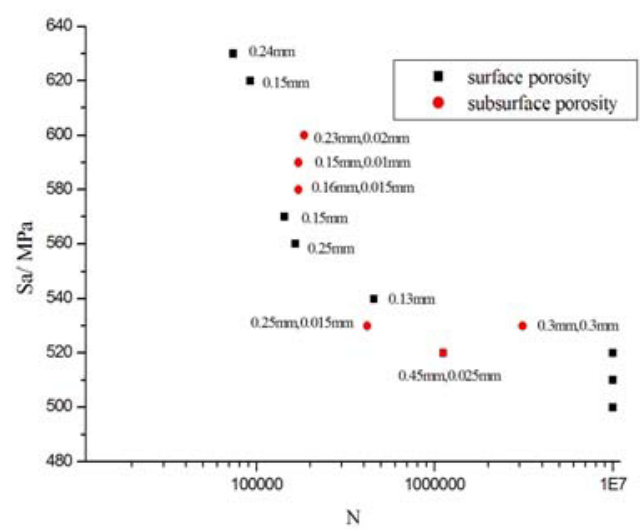

Fig.6 Fatigue life test result of sample

In order to quantitatively analyze specimen's fatigue life, fatigue test was carried out, and the fatigue life of the weld joint was analyzed. According to the size of the weld, the diameter of the fatigue specimens is $4.2 \mathrm{~mm}$. Fatigue life S-N curve was tested on the high frequency fatigue testing machine, and stress ratio was 0.15 . The fatigue life of the weld joint was studied by single point test method, and they were analyzed in the logarithmic coordinate system. The fatigue life test results is shown in Fig.6, and fatigue samples fractured at weld position. Morphology fracture surface was analysed by scanning electron microscopy (SEM). It was found that there were plenty of pore in fatigue samples. Crack originated from the pore position in specimen's surface or sub surface. some sample's crack source area has multiple many pores, fracture close to the crack source zone is mainly characteristic with cleavage fracture, and crack growth surface has obvious fatigue fracture characteristics. Fatigue fracture morphology under different stress as shown in Fig.7. The fatigue life of the specimen whose pore in surface is obviously lower than that of the specimen whose pore in subsurface. The greater the pore, the lower fatigue life. The existence of the pore induced the formation of fatigue crack, and reduced weld's fatigue life significantly. 

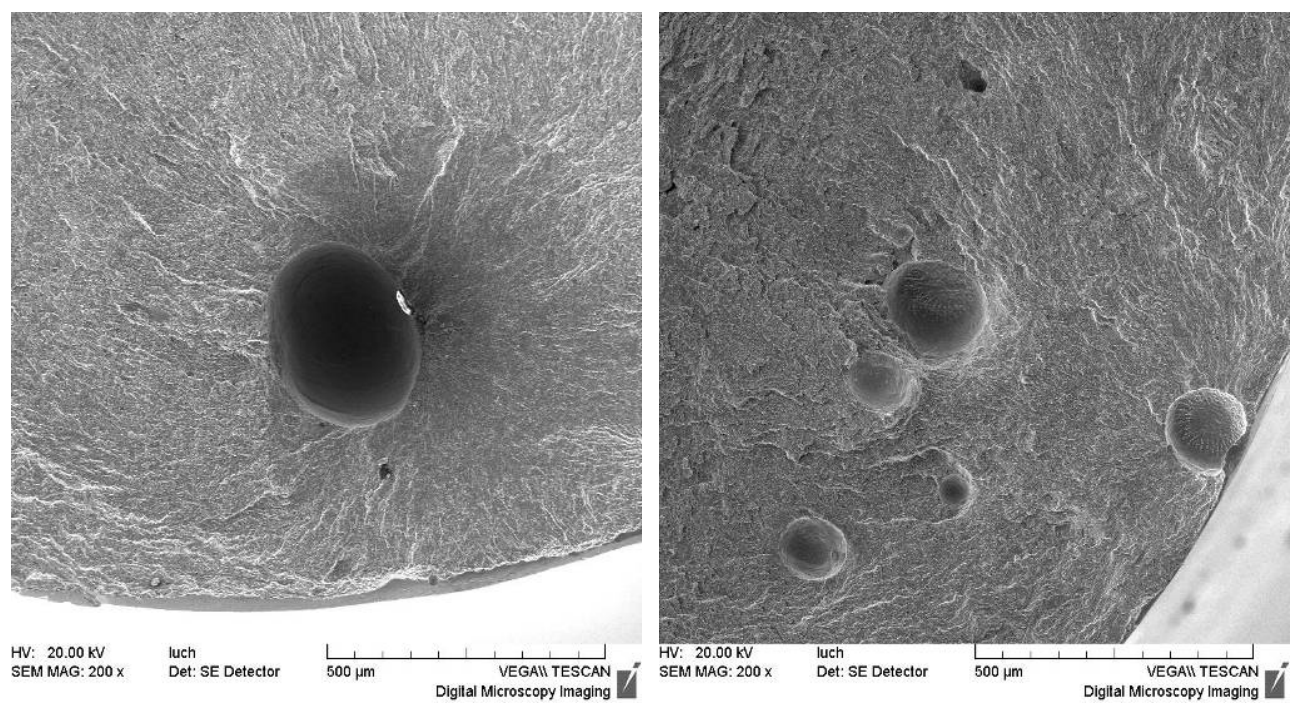

Fig.7 Morphology of fatigue fracture (a)530MPa(b)620MPa

\section{Conclusions}

(1)Tensile strength, impact absorption energy and cutting performance of X80 pipeline steel welded joint meet the requirement of related standards.

(2) Failure of the weld is fatigue failure, and the crack initiated from weld fusion near pipe body and developed along the weld. Porosity defect in the weld reduce its bearing capacity, and promoted the formation and development of fatigue crack.

(3) Fatigue strength and life of the weld has great relationship with the size and distribution of the porosity. The greater the porosity, the more close to the surface, the decrease of fatigue life is more obvious.

\section{References}

1. API Spec 5L:2012 Specification for line pipe. American Petroleum Institute[S].

2. API Std 1104:2007 Welding of pipelines and related facilities. American Petroleum Institute [S].

3. SY/T 7027-2014 Longitudinal submerged arc welded pipe for use as marine riser. Standard of the people's Republic of China Petroleum and natural gas industry[S].

4. SY/T 0452-2012 Standard for welding procedure qualification of oil and gas metal pipeline.Standard of the people's Republic of China Petroleum and natural gas industry[S]. 